\title{
Deneysel Renal iskemi Reperfüzyon Modelinde Akciğer Dokusunda Oksidan Hasarın Incelenmesi Ve Klorojenik Asit (CGA) Kullanımının Koruyucu Etkileri
} Investigation of Oxidative Damage of Lung Tissue in Experimental Renal Ischemia Reperfusion Model and The Protective Effects of Chlorogenic Acid (CGA)

\section{Ayhan Tanyeli', Derya Guzel²}

1 Atatürk Üniversitesi Tıp Fakültesi, Fizyoloji A.D.,Erzurum ${ }^{2}$ Sakarya Üniversitesi Tıp Fakültesi, Fizyoloji A.D.,Sakarya

Yazıșma Adresi / Correspondence: Derya Güzel

Sakarya Üniversitesi Eğitim ve Araştırma Hastanesi Nöroloji Kliniği /SAKARYA T: +90 5541936443 E-mail: deryaguzel@sakarya.edu.tr Geliş Tarihi / Received : 15.05.2018 Kabul Tarihi / Accepted : 31.05.2018

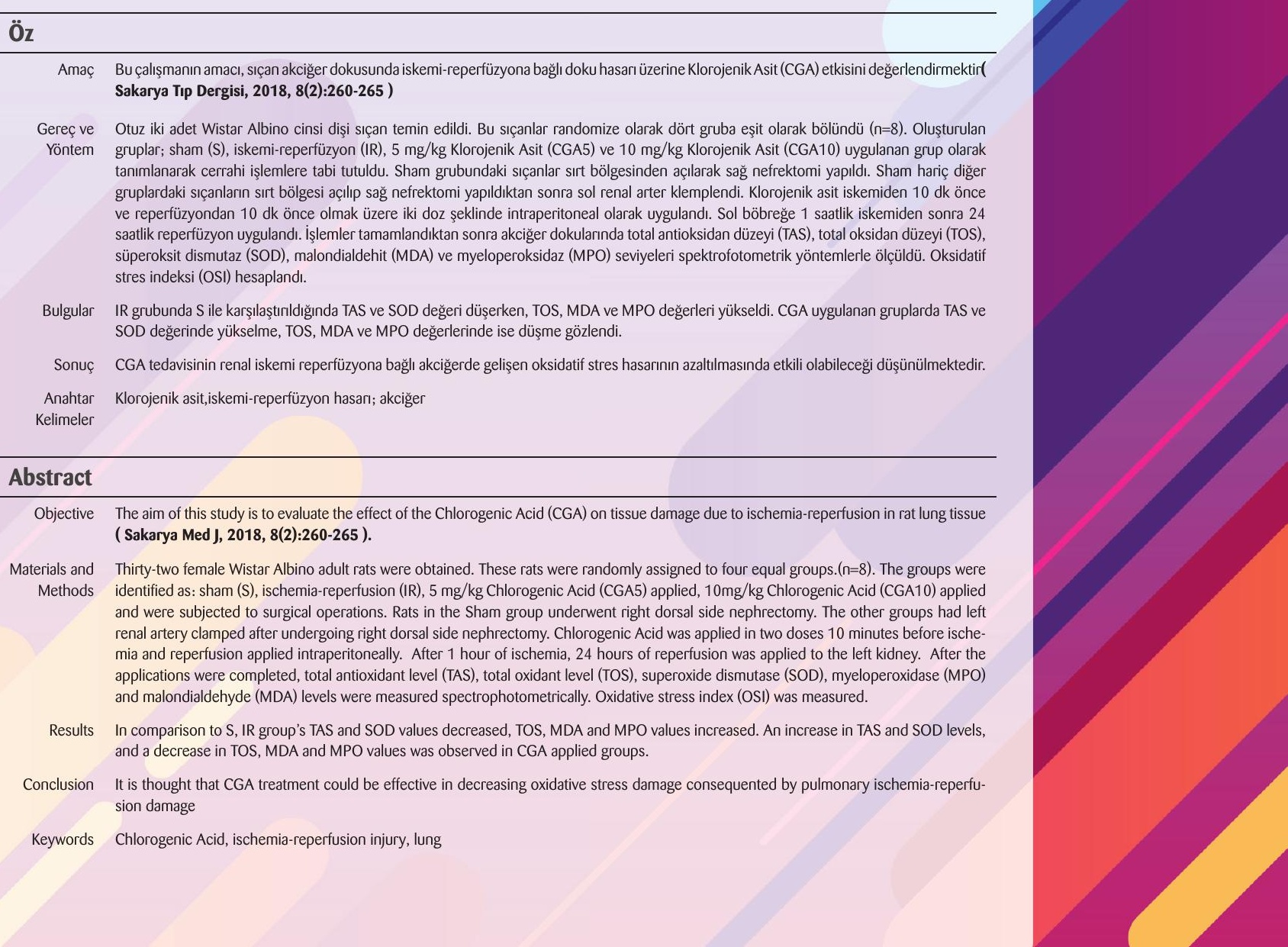


Sakarya TIp Dergisi 2018;8(2):260-265

\section{Giriş}

Akut böbrek yetmezliğiyle sonuçlanan böbrek iskemi/reperfüzyon hasarı, yüksek mortalite oranı sebebiyle major bir klinik problemdir. ${ }^{1,2}$ Kan akımının uzun süreli kesilmesi, iskemik hasara neden olurken, iyileşme süreci ile birlikte kan akışının restorasyonu paradoksal olarak reperfüzyon (IR) hasarına neden olur. Bu hasarın etyolojisinde kesin sebep bilinmemekle birlikte oksidatif stres ve reaktif oksijenlerin oluşumunun anahtar rol oynadığına inanılmaktadır. Renal IR böbrekte lokal hasara neden olurken, artmış pulmoner kapiller permeabilite, ödem ve nötrofil infiltrasyonu ile karakterize olan akciğer hasarına da neden olur. ${ }^{3}$ Kan akımının kesilmesi akciğerlerde polimorfonükleer lökositler (PMN) dahil olmak üzere kan hücrelerinin birikmesine yol açan ajanların salınmasını uyarır. ${ }^{4}$ Nötrofil aktivasyonu ile, toksik ajanların salımıyla akut solunum yetmezliği de meydana gelebilir. $^{5}$

Dokularda toksik oksidanların zararlı etkilerini ortadan kaldıran çeşitli antioksidan savunma mekanizmalarının olduğu bilinmektedir. Oksidan/antioksidan dengenin oksidanlar lehine değişmesi oksidatif doku hasarına yol açar. ${ }^{6}$ Süperoksit dismutaz (SOD), reaktif oksijen radikallerine (ROS) bağlı lipid peroksidasyonuna karşı hasarı önler. ${ }^{7}$ Antioksidanlar; hücre zarı lipidlerinin yanısıra proteinler, nükleik asitler ve karbonhidratlar gibi hedef molekülleri de oksidasyona karşı korur. ${ }^{6}$ Total oksidan düzeyi (TOS) ölçümü, lipit peroksidasyonu ve oksidatif stresin hassas bir indeksini sağlar. ${ }^{8}$ Total antioksidan düzeyi (TAS), reaktif oksijen türlerini temizleyerek IR aracılı oksidatif hasara karşı dokuları korur. TOS/TAS oranı oksidatif stres derecesinin bir göstergesi olan oksidatif stres indeksi (OSI) olarak adlandırılmaktadır. Torun ve arkadaşlarının yaptığı bir çalışmada, TAS, TOS ve OSI parametrelerinin ölçülmesinin klinik tanı sırasında sadece oksidatif ve/veya antioksidatif durumu göstermediği, aynı zamanda tedavi takibinde de önemli rol oynadığı bildirilmiştir.9

Klorojenik asit (5-0-caffeoylquinic asit, CGA), hidroksisinnamik asit familyasından bir fenolik bileşiktir. Bu polifenol, anti-oksidan, anti-enflamatuar, antilipidemik, antidiyabetik ve antihipertansif aktivitelere sahiptir. ${ }^{10}$ CGA'nın böbrek iskemi/reperfüzyon hasarına etkisi ve iskemi/reperfüzyon sırasında oluşan oksidatif stresle olan ilişkisi ile ilgili çalışmaya literatürde rastlanmamıştır. Bu çalışmanın amacı, deneysel renal IR modelinde meydana gelen akciğer oksidan hasarını incelemek ve bu hasarda yeni bir alternatif olarak CGA'nın olası koruyucu etkilerini biyokimyasal biyobelirteçlerle araştırmaktır.

\section{Gereç Ve Yöntem}

\section{Deney Hayvanlarının Belirlenmesi ve Cerrahi Teknikler:}

Atatürk Üniversitesi Hayvan Deneyleri Yerel Etik Kurulu'ndan etik onay alındıktan sonra, yetişkin otuz iki adet Wistar albino dişi sıçan (12-16 haftalık 200-250 gr.) üzerinde deneyler gerçekleştirildi. Sıçanlar, su ve standart sıçan yemi ile ad libitum beslendi. 12 saat aydınlık karanlık siklusu olan ortamda tutuldu. Sıçanlara yapılan deneysel uygulamalar intraperitoneal olarak uygulanan ketamin $(75 \mathrm{mg} / \mathrm{kg})$ ve ksilazin $(8 \mathrm{mg} / \mathrm{kg}$ ) anestezisi altında yapıldı. Hayvanlar her grupta 8 hayvan olacak şekilde rastgele 4 gruba bölündü: Sham grubu (S), iskemi reperfüzyon (IR), iskemi reperfüzyon ve $5 \mathrm{mg} / \mathrm{kg}$ CGA uygulanan grup (CGA5), iskemi reperfüzyon ve $10 \mathrm{mg} / \mathrm{kg}$ CGA uygulanan grup (CGA10). Sham grubunda deney hayvanları sırt bölgesinden açııp sağ nefrektomi yapııldıtan sonra sırt bölgeleri kapatıldı. IR'de sıçanların sırt bölgesi açılıp sağ nefrektomiden sonra sol renal arter klemplendi. Sol böbreğe 1 saatlik iskemiden sonra 24 saatlik reperfüzyon uygulandı. CGA5 ve CGA10 tedavi grupları olup, IR'de yapılan cerrahi işlemlere ek olarak sırası ile $5 \mathrm{mg} / \mathrm{kg}$ ve 10 
$\mathrm{mg} / \mathrm{kg}$ Klorojenik asit iskemiden $10 \mathrm{dk}$ önce ve reperfüzyondan 10 dk önce olmak üzere iki doz şeklinde sıçanlara uygulandı.

\section{Biyokimyasal analizler:}

Analiz için dokulara fosfat tamponu ilave edilerek \%10'luk homojenat oluşturuldu ve buz üzerinde 1-2 dakika 12,000 rpm'de homojenleştirildi (IKA, Almanya). Homojenat doku örnekleri, süpernatantı elde etmek için 5000 rpm'de 30 dakika boyunca $+4{ }^{\circ} \mathrm{C}$ 'de santrifüj edildi. Elde edilen süpernatantlar, TAS, TOS, SOD, malondialdehit (MDA) ve myeloperoksidaz (MPO) seviyeleri için test edildi.

Homojenattaki MDA seviyeleri, Ohkawa ve arkadaşları tarafından tarif edilen yöntem kullanılarak analiz edildi. ${ }^{11}$ TAS (Rel Assay Diagnostics, Ref. No. RL0024) ve TOS (Rel Assay Diagnostics, Ref. No.:RL0005) analizi ticari kitler kullanılarak yapıldı. OSI belirtilen formül ile hesaplandı: OSI = ([TOS, mmol H2O2 eşdeğer / L] / [TAS, mmol Trolox eşdeğeri / L] x 10). ${ }^{12}$

MPO, hidrojen peroksit ( $\mathrm{H} 2 \mathrm{O} 2$ ) varlığında MPO ve o-dianisidin oksidasyonunun sonucu olarak şekillenen sarımsı-turuncu renkli kompleks formun $460 \mathrm{~nm}$ dalga boyunda absorbansın kinetik ölçümü esas alınarak yapıldı. SOD, enzimatik reaksiyonların sonucu olarak oluşan süperokside SOD enziminin etkisinin yetersiz olduğu durumlarda, spektrofotometrede $560 \mathrm{~nm}$ dalga boyundaki bu reaksiyonun inhibisyon derecesini ölçerek formazan boyası oluşturmak üzere tetrazolyum tuzu ile reaksiyona sokulduktan sonra hesaplandı. ${ }^{13}$

\section{İstatistiksel Analiz Yöntemleri:}

Verilerin istatistiksel analizleri SPSS 21.0 programı (SPSS Inc. and Lead Tech. Inc. Chicago. USA) kullanılarak yapıldı. Gruplarda elde edilen değerler ortalama değer \pm standart sapma olarak ifade edildi. Gruplar arasında biyokimyasal parametrelerin karşılaştııımasında iki grup arasındaki farkın anlamlılık derecesi Mann Whitney U testi ile değerlendirildi. i̇statistiksel değerlendirmede $p<0.05$ ise anlamlı kabul edildi.

\section{Bulgular}

Deneyseluygulamalaresnasındamorbiditevemortaliteizlenmedi.IRgrubundaTAS $(1.697 \pm 0.141$ 'den $1.090 \pm 0.122$ 'e, $p=0.000)$ ve SOD $(424.316 \pm 33.039$ 'den $208.594 \pm 12.480$ 'e, $p=0.000$ ) seviyesi düsserken, TOS (7.925 \pm 0.599 den $\left.12.254 \pm 0.619^{\prime} \mathrm{e}, \mathrm{p}=0.000\right)$, OSI $(0.470 \pm 0.064$ 'den $1.134 \pm 0.125$ 'e; $p=0.000)$, MPO $(216136.033 \pm 18823.201$ 'den $365076.100 \pm 41391.278$ 'e, $\mathrm{p}=0.041)$ ve MDA $(56.533 \pm 5.059$ 'den $90.895 \pm 12.932$ 'e, $\mathrm{p}=0.000)$ seviyeleri arttı.

Sham grubu CGA5 ile karşlaş̧ıııldığında; TAS (1.697 \pm 0.141 'den $1.465 \pm 0.188$ 'e, $p=0.015$ ) ve SOD (424.316 \pm 33.039 'den $352.9673 \pm 30.39861$ 'e, $\quad p=0.001)$ düşerken, TOS (7.925 \pm 0.599 den $9.149 \pm 0.925$ 'e, $p=0.007$ ), OSI ( $0.470 \pm 0.064$ 'den $0.636 \pm 0.128$ ' $\mathrm{e} ; \mathrm{p}=0.006$ ), MPO (216136.033 \pm 18823.201 'den $263789.6629 \pm 23871.39373$ 'e, $\rho=0.001)$ ve MDA (56.533 \pm 5.059 'den 62.302 \pm 4.180 'e, $p=0.026$ ) seviyeleri arttı.

IR ve CGA5 karşılaştıııldığında; TAS $(1.090 \pm 0.122$ "'den $1.465 \pm 0.188$ 'e, $p=0.000)$ ve SOD $(208.5945 \pm 12.48066$ 'den $352.9673 \pm 30.39861$ 'e, $p=0.000)$ artarken, TOS $(12.254 \pm 0.619$ 'den $9.149 \pm 0.925 ' \mathrm{e}, \quad \rho=0.000)$, OSI $\quad\left(1.134 \pm 0.125^{\prime}\right.$ den $\left.\quad 0.636 \pm 0.128^{\prime} \mathrm{e} ; \quad \rho=0.000\right) \quad$ MPO (365076.1006 \pm 41391.27882 'den $263789.6629 \pm 23871.39373$ 'e, $p=0.000)$ ve MDA
Sakarya Tıp Dergisi $2018 ; 8(2): 260-265$

TANYELi ve Ark. Uzak Doku Oksidan Hasarında Klorojenik Asit Kullanımınin Koruyucu Etkileri 
Sakarya TIp Dergisi 2018;8(2):260-265

\begin{tabular}{|c|c|c|c|c|c|c|}
\hline $\begin{array}{l}\text { Deney Grupları } \\
\mathrm{n}=8\end{array}$ & $\begin{array}{l}\text { TAS(mmol/L) } \\
\text { ort } \pm S . D\end{array}$ & $\begin{array}{l}\mathrm{TOS}(\mu \mathrm{mol} / \mathrm{L}) \\
\text { ort } \pm \text { S.D }\end{array}$ & $\begin{array}{c}\text { OSI } 0 \\
\text { ort } \pm S . D\end{array}$ & $\begin{array}{l}\text { SOD }(\mathrm{U} / \mathrm{mg} \\
\text { protein) } \\
\text { ort } \pm \text { S.D }\end{array}$ & $\begin{array}{l}\text { MPO }(\mathrm{U} / \mathrm{g} \\
\text { protein) } \\
\text { ort } \pm \text { S.D }\end{array}$ & $\begin{array}{l}\text { MDA ( } \mu \mathrm{mol} / \mathrm{g} \\
\text { protein) } \\
\text { ort } \pm \text { S.D }\end{array}$ \\
\hline $\begin{array}{l}\text { Sham Kontrol } \\
\text { Grubu (S) }\end{array}$ & $1.697 \pm 0.141$ & $7.925 \pm 0.599$ & $0.470 \pm 0.064$ & $424.316 \pm 33.039$ & $\begin{array}{l}216136.033 \\
\pm 18823.201\end{array}$ & $56.533 \pm 5.059$ \\
\hline $\begin{array}{l}\text { iskemi- } \\
\text { reperfüzyon } \\
\text { Grubu (IR) }\end{array}$ & $1.090 \pm 0.122$ & $12.254 \pm 0.619$ & $1.134 \pm 0.125$ & $208.594 \pm 12.480$ & $\begin{array}{l}365076.100 \\
\pm 41391.278\end{array}$ & $90.895 \pm 12.932$ \\
\hline $\begin{array}{l}\text { İskemi- } \\
\text { reperfüzyon + } 5 \\
\text { mg/kg Klorojenik } \\
\text { asit Grubu (CGA5) }\end{array}$ & $1.465 \pm 0.188$ & $9.149 \pm 0.925$ & $0.636 \pm 0.128$ & $352.967 \pm 30.398$ & $\begin{array}{l}263789.662 \\
\pm 23871.393\end{array}$ & $62.302 \pm 4.180$ \\
\hline $\begin{array}{l}\text { İskemi- } \\
\text { reperfüzyon + } \\
10 \text { mg/kg Kloro- } \\
\text { jenik asit Grubu } \\
\text { (CGA10) }\end{array}$ & $1.655 \pm 0.311$ & $8.481 \pm 1.005$ & $0.533 \pm 0.1505$ & $392.154 \pm 41.005$ & $\begin{array}{l}228443.203 \\
\pm 22579.321\end{array}$ & $57.748 \pm 5.272$ \\
\hline $\begin{array}{l}\text { p değeri } \\
\text { (gruplar arası } \\
\text { anlamlılık } \\
\text { karşılaştırmaları) }\end{array}$ & $\begin{array}{c}0.000 \text { (S-IR) } \\
0.000 \text { (IR-CGA5) } \\
0.000 \text { (IR-CGA10) } \\
0.015 \text { (S-CGA5) }\end{array}$ & $\begin{array}{c}0.000 \text { (S-IR) } \\
0.000 \text { (IR-CGA5) } \\
0.000(\text { IR-CGA10) } \\
0.007 \text { (S-CGA5) }\end{array}$ & $\begin{array}{c}0.000(\mathrm{~S}-\mathrm{IR}) \\
0.000(\mathrm{IR}-\mathrm{CGA}) \\
0.000 \text { (IR-CGA10) } \\
0.006 \text { (S-CGA5) }\end{array}$ & $\begin{array}{c}0.000 \text { (S-IR) } \\
0.000 \text { (IR-CGA5) } \\
0.000 \text { (IR- } \\
\text { CGA10) } \\
0.001 \text { S-CGA5) }\end{array}$ & $\begin{array}{c}0.041 \text { (S-IR) } \\
0.000 \text { (IR- } \\
\text { CGA5) } \\
0.000 \text { (IR- } \\
\text { CGA10) } \\
0.001(\text { S-CGA5) }\end{array}$ & $\begin{array}{c}0.000(\mathrm{~S}-\mathrm{IR}) \\
0.000(\mathrm{IR}-\mathrm{CGA} 5) \\
0.000(\mathrm{IR}- \\
\text { CGA10) } \\
0.026(\mathrm{~S}-\mathrm{CGA} 5)\end{array}$ \\
\hline
\end{tabular}

\section{Tartışma}

Akut böbrek hasarının ana nedenlerinden olan renal IR hasarı böbreğe kan akımının azalması veya kesilmesi sonrası tekrar kanlanması ile meydana gelir. Koroner arter bypassı, abdominal aort anevrizması tamiri, böbrek operasyonları, renal transplantasyon, travma, şok ve sepsis IR görülen başlıca durumlardır. ${ }^{14-16}$ IR hasarına bağlı gelişen akut böbrek yetmezliği önemli bir sağlık problemi olmakla birlikte ne yazık ki günümüzde tedavi edici veya koruyucu herhangi bir ajan bulunmamaktadır. IR hasar mekanizmalarında birçok bağımsız faktörün rol oynadığı düşünülmektedir. ${ }^{17}$ Bunlar arasında iskemik dokunun reperfüzyonuna bağlı olarak ortaya çıkan ROS, IR hasarının patogenezinde önemli bir rol oynar. Aşırı ROS oluşumu ve IR sırasında antioksidan savunma sisteminin bozulması oksidatif hasara neden olur. ${ }^{18}$ Sunduğumuz bu çalışma ile oksidatif stres durumunu değerlendirmek için TAS, TOS ve OSI seviyelerini ölçtük ve CGA'nın TAS'ı arttırarak, TOS ve OSI'yi azaltarak böbrek IR'nin neden olduğu akciğer hasarından koruyabildiğini gözlemledik. TOS, lipit peroksidasyonu ve oksidatif stresin hassas bir indeksini sağlar. ${ }^{8}$ TAS, reaktif oksijen türlerini temizleyerek IR aracılı oksidatif hasara karşı canlı dokuları korur. TOS/TAS oranı oksidatif stres derecesinin bir göstergesi olan "OSI" olarak adlandırılmaktadır. ${ }^{9}$ Torun ve arkadaşlarının yaptığı bir çalışmada, bu parametrelerin ölçülmesinin tanı ve tedavi takibinde de önemli rol oynadığı bildirilmiştir. ${ }^{9}$ MDA, lipid peroksidasyonunun son ürünüdür ve iskemi/reperfüzyon ilişkili oksidatif hasarın değerlendirilmesinde önemli parametrelerden biridir. ${ }^{19}$ Lipid peroksidasyonu; bozulmuş hücre zarı geçirgenliği, azalmış membran potansiyeli ve hücre hasarına yol açar. MDA oluşumu ile hücre hasarı daha da artmaktadır. ${ }^{20}$ Hücrede oksidan olarak bilinen bir başka parametre MPO enzimidir. ${ }^{21}$ 
Klorür iyonları varlığında MPO, hidrojen peroksiti hipokloröz asite indirger. Hipokloröz asit güçlü bir oksidandır ve kolayca çeşitli biyolojik moleküller ile reaksiyona girebildiğinden dolayı doku hasarına yol açar . ${ }^{21}$

Klorojenik asit; anti-oksidan, anti-enflamatuar, antilipidemik, antidiyabetik ve antihipertansif aktiviteleri içeren birçok özelliğe sahiptir. ${ }^{10}$ Kafeik ve kinik asitlerin esterleştirilmesiyle oluşan CGA, doğada en bol bulunan polifenollerden biridir. ${ }^{22}$ İnsan diyetindeki kolay erişilebilirliğinden dolayı, çeşitli hayvan modellerinde anti-enflamatuar, antibakteriyel, antioksidan ve antikanserojenik aktiviteleri içeren biyolojik fonksiyonlarını araştırmak için geniş bir çalışma yapılmışıı. ${ }^{23,24}$ innsan akciğer kanser hücre hattında (A549), CGA'nın hücresel antioksidan enzimin upregülasyonunu başlatarak antioksidan özelliği gösterilmiştir. ${ }^{25}$ CGA'nın diyabetik nefropatiye karşı antioksidan özelliği ile renoprotektif etkisi gösterilmiştir. ${ }^{26}$ CGA'nın fare makrofaj hücre hattında (RAW264.7) Janus kinaz-2/sinyal dönüştürücü ve transkripsiyon aktivatörü (JAK2/STAT3) aktivasyonunu inhibe ederek lipopolisakkaridle indüklenen inflamasyonu baskıladığı gösterilmiştir. ${ }^{27}$ CGA'nın glutamatla indüklenen kortikal nöron hasarına karşı, endojen ROS birikimini baskılayarak ve SOD aktivitesinin artışıly enzimatik antioksidan sistemi aktive ederek koruyucu bir ajan olduğu gösterilmiştir. ${ }^{28}$ CGA tedavisi, depolama sırasında nektarin meyvesinin O2- üretim oranını, $\mathrm{H} 2 \mathrm{O} 2$ içeriğini önemli ölçüde azaltmıştı. Hasat sonrası olgunlaşma sırasında CGA nektarin meyvesindeki oksidatif hasarı azaltarak etkisini göstermiş̧tir. ${ }^{29}$ CGA'nın interlökin-1beta (IL-1) ile uyarılmış insan kondrosit hücre hattında (SW-1353) inflamatuar yanıtları önlediği rapor edilmiştir. ${ }^{30}$ CGA, metotreksat ile indüklenmiş karaciğer hasarına karşı metotrekrat ile azalan SOD, katalaz (CAT) gibi antioksidanlar arttırarak antioksidan özelliği sayesinde hepatoprotektif etki göstermiştir. ${ }^{31}$ Yüksek yağlı diyetle beslenen sıçanlara CGA uygulamasının karaciğer ve böbreklerde antioksidan durumu artıırdı̆̆ı yüksek dansiteli lipoprotein (HDL) miktarını arttırdığı ve insulin miktarını azalttığı gösterilmiştir.32 CGA'nın, fosfaldilinositol 3-kinaz/protein kinaz aracilı (PI3K/Akt) nükleer faktör E2-ilişkili faktör 2/hem oksijenaz-1 (Nrf2/HO-1) yolağının aktivasyonu yoluyla hidrojen peroksit kaynaklı oksidatif hasara karşı fare kalvarisi kaynaklı hücre hattını (MC3T3-E1) korumuş olduğu ve osteoporoz tedavisinde etkili bir ilaç olabileceği gösterilmiştir. ${ }^{33}$ CGA, Toll-benzeri reseptör 4 aracılı NF- B (TLR4/NF- B) sinyal yolunu inhibe ederek lipopolisakkarit indüklü akut böbrek hasarını azaltmıştır. ${ }^{34} \mathrm{CGA}$, sıçan miyokardında isoproterenolun neden olduğu miyokardiyal oksidatif stresi azaltmıştır. ${ }^{35}$

Tüm bu veriler ışığında CGA'nın antioksidatif özellikleri nedeniyle IR hasarında birtakım roller üstlendiğini belirlendi. Bu çalışmada CGA'nın böbrek iskemi/reperfüzyon modelindeki etkileri oksidatif stres parametreleri olan SOD, TAS, TOS, OSI, MDA ve MPO düzeylerini ölçerek belirlendi. Bu veriler, CGA'nın böbrek iskemi reperfüzyon kaynaklı akciğer hasarına karşı koruyucu etkili olduğunu göstermektedir ve gelecekte yeni bir tedavi ajanı olarak denenebilir.
Sakarya Tıp Dergisi

$2018 ; 8(2): 260-265$

TANYELi ve Ark

Uzak Doku Oksidan Hasarında Klorojenik

Asit Kullanıminin Koruyucu Etkileri 
1. Yun Y, Duan WG, Chen P, Wu HX, Shen ZQ, Qian ZY et al. Ischemic postconditioning modified renal oxidative stress and lipid peroxidation caused by ischemic reperfusion injury in rats. Transplant Proc, 2009; 41 : 3597-3602.

2. Fadillioglu $\mathrm{E}$, Kurcer Z, Parlakpinar H, Iraz M, Gursul C. Melatonin treatment against remote organ injury induced by renal ischemia reperfusion injury in diabetes mellitus. Arch Pharm Res, 2008; 31: 705-712.

3. Anner H, Kaufman Jr RP, Kobzik L, Valeri CR, Shepro D, Hechtman HB. Pulmonary leukosequestration induced by hind limb ischemia. Annals of surgery, 1987; 206: 162.

Sakarya TIp Dergis 2018;8(2):260-265

4. Stallone RJ, Lim RC, Blaisdell FW. Pathogenesis of the pulmonary changes following ischemia of the lower extremities. The Annals of thoracic surgery, 1969; 7: 539-549.

5. Windsor A, Mullen P, Fowler A, Sugerman H. Role of the neutrophil in adult respiratory distress syndrome. BJS, 1993; 80: 10-17.
6. Rangan U, Bulkley GB. Prospects for treatment of free radical-mediated tissue injury. Br Med Bull, 1993; 49: 700-718.

7. Liu YH, Zhang ZB, Zheng YF, Chen HM, Yu XT, Chen XY, et al. Gastrop rotective effect of andrographolide sodium bisulfite against indomethacin-induced gastric ulceration in rats. Int Immunopharmacol, 2015; 26 : 384-391.

8. Demirpence O, Sevim B, Yildirim M, Ayan Nurlu N, Mert D, Evliyaoglu O. Serum paraoxonase, TAS, TOS and ceruloplasmin in brucellosis. Int J Clin Exp Med, 2014; 7: 1592-1597.

9. Aycicek A, Ipek A. Maternal active or passive smoking causes oxidative stress in cord blood. Eur J Pediatr, 2008; 167: 81-85.

10. Santana-Galvez J, Cisneros-Zevallos L, Jacobo-Velazquez DA. Chlorogenic Acid: Recent Advances on Its Dual Role as a Food Additive and a Nutraceutical against Metabolic Syndrome. Molecules, 2017; 22.

11. Ohkawa H, Ohishi N, Yagi K. Assay for lipid peroxides in animal tissues by thiobarbituric acid reaction. Analytical biochemistry, 1979; 95: 351-358.

12. Erel O. A new automated colorimetric method for measuring total oxidant status. Clinical biochemistry, 2005; 38: 1103-1111.

13. Sun Y, Oberley LW, Li Y. A simple method for clinical assay of superoxide dismutase. Clinical chemistry, 1988; 34: 497-500.

14. Dasta JF, Kane-Gill SL, Durtschi AJ, Pathak DS, Kellum JA. Costs and outcomes of acute kidney injury (AKI) following cardiac surgery. Nephrol Dial Transplant, 2008; 23: 1970-1974.

15. Perico N, Cattaneo D, Sayegh MH, Remuzzi G. Delayed graft function in kidney transplantation. Lancet, 2004; 364: 1814-1827.

16. Roodnat II, Mulder PG, Van Riemsdijk IC, JN IJ, van Gelder T, Weimar W. Ischemia times and donor serum creatinine in relation to renal graft failure. Transplantation, 2003; 75: 799-804.

17. Ozlulerden Y, Toktas C, Aybek H, Kucukatay V, Sen Turk N, Zumrutbas AE. The renoprotective effects of mannitol and udenafil in renal ischemiareperfusion injury model. Investig Clin Urol, 2017; 58: 289-295.

18. Katugampola S, Davenport A. Emerging roles for orphan G-proteincoupled receptors in the cardiovascular system. Trends Pharmacol Sci, 2003; $24: 30-35$

19. Gutteridge JM. Lipid peroxidation and antioxidants as biomarkers of tissue damage. Clin Chem, 1995; 41: 1819-1828.

20. Girotti AW. Lipid hydroperoxide generation, turnover, and effector action in biological systems. J Lipid Res, 1998; 39: 1529-1542.

21. Lavelli V, Peri C, Rizzolo A. Antioxidant activity of tomato products as studied by model reactions using xanthine oxidase, myeloperoxidase, and copper-induced lipid peroxidation. J Agric Food Chem, 2000; 48: 1442-1448.
22. Suzuki A, Yamamoto N, Jokura H, Yamamoto M, Fujii A, Tokimitsu I, et al. Chlorogenic acid attenuates hypertension and improves endothelial function in spontaneously hypertensive rats. J Hypertens, 2006; 24: 1065-1073

23. Bonita JS, Mandarano M, Shuta D, Vinson J. Coffee and cardiovascular disease: in vitro, cellular, animal, and human studies. Pharmacol Res, 2007; 55: 187-198.

24. dos Santos MD, Almeida MC, Lopes NP, de Souza GE. Evaluation of the anti-inflammatory, analgesic and antipyretic activities of the natural polyphenol chlorogenic acid. Biol Pharm Bull, 2006; 29: 2236-2240.

25. Feng R, Lu Y, Bowman LL, Qian Y, Castranova V, Ding M. Inhibition of activator protein-1, NF-kappaB, and MAPKs and induction of phase 2 detoxifying enzyme activity by chlorogenic acid. J Biol Chem, 2005; 280: 27888-27895

26. Bao L, Li J, Zha D, Zhang L, Gao P, Yao T. Chlorogenic acid prevents diabetic nephropathy by inhibiting oxidative stress and inflammation through modulation of the Nrf2/HO-1 and NF-kB pathways. Int Immunopharmacol, 2018; 54: 245-253.

27. Kim SH, Park SY, Park YL, Myung DS, Rew JS, Joo YE. Chlorogenic acid suppresses lipopolysaccharideinduced nitric oxide and interleukin1beta expression by inhibiting JAK2/STAT3 activation in RAW264.7 cells. Mol Med Rep, 2017; 16: 9224-9232.

28. Rebai O, Belkhir M, Sanchez-Gomez MV, Matute C, Fattouch S, Amri M. Differential Molecular Targets for Neuroprotective Effect of Chlorogenic Acid and its Related Compounds Against Glutamate Induced Excitotoxicity and Oxidative Stress in Rat Cortical Neurons. Neurochem Res, 2017 42: 3559-3572

29. Xi Y, Jiao W, Cao J, Jiang W. Effects of chlorogenic acid on capacity of free radicals scavenging and proteomic changes in postharvest fruit of nectarine. PLoS One, 2017; 12: e0182494.

30. Liu CC, Zhang Y, Dai BL, Ma YJ, Zhang Q, Wang Y,et al. Chlorogenic acid prevents inflammatory responses in IL1betastimulated human SW1353 chondrocytes, a model for osteoarthritis. Mol Med Rep, 2017; 16: 1369 1375.

31. Ali N, Rashid S, Nafees S, Hasan SK, Shahid A, Majed F,et al. Protective effect of Chlorogenic acid against methotrexate induced oxidative stress, inflammation and apoptosis in rat liver: An experimental approach. Chem Biol Interact, 2017: 272: 80-91.

32. Budryn G, Zaczynska D, Zyzelewicz D, Grzelczyk J, Zdunczyk Z, Juskiewicz J. Influence of the Form of Administration of Chlorogenic Acids on Oxidative Stress Induced by High fat Diet in Rats. Plant Foods Hum Nutr 2017; 72: 184-191.

33. Han D, Chen W, Gu X, Shan R, Zou J, Liu G,et al. Cytoprotective effect of chlorogenic acid against hydrogen peroxide-induced oxidative stress in MC3T3-E1 cells through PI3K/Akt-mediated Nrf2/HO-1 signaling pathway. Oncotarget, 2017; 8: 14680-14692.

34. Ye HY, Jin J, Jin LW, Chen Y, Zhou ZH, Li ZY. Chlorogenic Acid Attenuates Lipopolysaccharide-Induced Acute Kidney Injury by Inhibiting TLR4/NFkappaB Signal Pathway. Inflammation, 2017; 40: 523-529.

35. Akila P, Vennila L. Chlorogenic acid a dietary polyphenol attenuates isoproterenol induced myocardial oxidative stress in rat myocardium: An in vivo study. Biomed Pharmacother, 2016; 84: 208-214. 